\title{
Ocorrência de Plantas Daninhas no Cultivo de Beterraba com Cobertura Morta e Adubação Orgânica ${ }^{1}$
}

\author{
Weed Occurrence in Sugar Beet Crop under Mulching and Organic Fertilization
}

\begin{abstract}
SEDIYAMA, M.A.N. ${ }^{2}$, SANTOS, M.R. ${ }^{3}$, VIDIGAL, S.M. ${ }^{2}$, SANTOS, I.C. ${ }^{4}$ e SALGADO, L.T. ${ }^{2}$
RESUMO - A cobertura do solo é prática importante na produção de hortaliças que também auxilia no controle de plantas daninhas. Praticamente, não existem pesquisas para o controle alternativo de plantas daninhas em beterraba, e são poucos os herbicidas indicados para a cultura. Neste trabalho, objetivou-se avaliar o efeito da cobertura do solo com palha de café ou bagaço de cana-de-açúcar e de doses de lodo de lagoa de decantação de águas residuárias de suinocultura na incidência de plantas daninhas e na produtividade de beterraba, cultivar Early Wonder. O experimento foi realizado na Fazenda Experimental da EPAMIG, em Oratórios-MG. Utilizou-se o esquema de parcelas subdivididas no delineamento experimental de blocos casualizados, com quatro repetições. Nas parcelas foram dispostos três tipos de cobertura do solo: bagaço de cana-de-açúcar, palha de café e ausência de cobertura, e nas subparcelas utilizaram-se cinco doses de lodo de lagoa de decantação de águas residuárias de suinocultura $\left(0,10,20,40\right.$ e $\left.60 \mathrm{t} \mathrm{ha}^{-1}\right)$. Aos 45 dias após o transplantio (DAT) das mudas foi avaliada a população de plantas daninhas, e aos 70 DAT realizou-se a colheita. A palha de café e o bagaço de cana-de-açúcar foram eficazes na redução da massa fresca total das plantas daninhas, devido ao efeito supressor da cobertura morta sobre as dicotiledôneas. Todavia, a massa seca de tiririca aumentou com o uso de palha de café, enquanto a massa seca das outras monocotiledôneas não apresentou diferença entre os três tratamentos. $\mathrm{O}$ aumento das doses de lodo promoveu redução linear da massa seca de monocotiledôneas, exceto de tiririca. A cobertura com palha de café proporcionou maior massa unitária de raiz e maior produtividade de raizes comerciais, independentemente das doses de lodo.
\end{abstract}

Palavras-chave: Beta vulgaris, supressão, dejeto de suíno.

\begin{abstract}
Soil covering is an important practice in vegetable production, also helping in weed control. There is almost no research involving alternative weed control in sugar beet and few herbicides are suitable for this crop. This work aimed to evaluate the effect of mulching using coffee husk and sugarcane bagasse, and doses of swine culture waste water sedimentation pond sludge on weed incidence and yield of sugar beet cultivar Early Wonder. The experiment, carried out at the EPAMIG Experimental Farm in Oratórios-MG, was arranged as a split-plot in a randomized block design with four replications. The plots consisted of three types of cover crops: sugarcane bagasse, coffee husk and no cover, and the split-plots of five doses of sludge from swine wastewater sedimentation pond $\left(0,10,20,40\right.$ and $\left.60 t \mathrm{ha}^{-1}\right)$. At 45 days after seedling transplanting (DAT), the weed population was evaluated and at 70 DAT, harvest was carried out. Coffee husk and sugarcane bagasse were effective in reducing the total fresh weight of weeds, mainly because of the suppressive effect of mulching on dicotyledonous weeds. Nut grass (Cyperus rotundus) dry mass increased with coffee husk, while dry mass of other monocots showed no difference among the three treatments. Increasing doses of sludge caused a linear reduction in the dry mass of monocots, except of nut grass. Coffee husk mulching provided the highest root unit weight and increased commercial root yield, regardless of the sludge doses.
\end{abstract}

Keywords: Beta vulgaris, suppression, swine manure.

Recebido para publicação em 2.12.2009 e na forma revisada em 12.11.2010.

2 Pesquisadores da EPAMIG Zona da Mata, Caixa Postal-216, 36570-000 Viçosa-MG, <marians@epamig.ufv.br>, <sanziomv@epamig.ufv.br>, <lsalgado@epamig.ufv.br>; ${ }^{3}$ Pesquisadora da EPAMIG SM-FERN, 36301-360 São João Del Rei-MG, <icsantos@epamig.br>; ${ }^{4}$ Professora da Universidade Estadual do Piauí - UESPI, Núcleo de Uruçuí, Rua Almir Benvindo S/N, Malvinas. 64860-000 Uruçuí-PI, <marleirs@yahoo.com.br>.

Planta Daninha, Viçosa-MG, v. 28, n. 4, p. 717-725, 2010 


\section{INTRODUÇÃO}

A beterraba (Beta vulgaris) é uma hortaliça de raiz tuberosa, sabor adocicado e coloração vermelha devido à presença de betalaínas substâncias antioxidantes que, aliadas aos altos conteúdos de vitaminas e minerais, tornam a beterraba importante na dieta humana (Kanner et al., 2001). A planta é originária da região europeia e norte-africana de clima temperado, razão pela qual se adapta melhor em clima ameno, sendo mais cultivada nas regiões Sudeste e Sul do Brasil, com produtividade variando entre 25 e $40 \mathrm{t} \mathrm{ha}^{-1} \mathrm{de}$ raízes (Horta et al., 2004; Carvalho \& Guzzo, 2008).

O desenvolvimento de técnicas alternativas de cultivo que visam reduzir o uso de agrotóxicos e de fertilizantes químicos, podendo diminuir os custos de produção e aumentar a qualidade do produto, é de interesse dos agricultores e dos consumidores. $\mathrm{O}$ manejo adequado das plantas daninhas é fator determinante para se alcançar boa produtividade no cultivo da beterraba, uma vez que a competição entre as plantas resulta em perdas significativas. Carvalho et al. (2008) verificaram que a convivência da beterraba com as plantas daninhas, durante todo o ciclo, reduziu a produtividade em mais de $70 \%$ em relação à mantida no limpo, cuja produtividade foi de 44,92 $\mathrm{t} \mathrm{ha}^{-1}$. A redução na produtividade pode chegar a $100 \%$, dependendo das condições ambientais e do manejo da cultura (Horta et al., 2004).

As plantas de beterraba apresentam porte baixo, o que favorece o crescimento das plantas daninhas, que concorrem com a cultura por luz, água e nutrientes desde o início de seu estabelecimento, além de serem hospedeiras de pragas e doenças; por isso, devem ser manejadas de modo a minimizar a sua interferência na cultura. Devido ao espaçamento estreito entre linhas, a capina pode danificar as raizes e comprometer a qualidade e a produtividade, se cuidados especiais não forem tomados na operação (Stal \& Dusky, 2009). Para evitar quedas de produtividade na beterraba, devem-se estabelecer métodos de controle, reduzindo a interferência em períodos que variam de 14 a 63 dias iniciais (Tozani et al., 2006).
A utilização de herbicidas apresenta como forte limitação o fato de haver somente dois deles registrados (metamitron e paraquat) para a cultura no Brasil (Carvalho, 2009). Além disso, essa tecnologia exige conhecimento técnico para aplicação e seu uso não é permitido em cultivos agroecológico e orgânico (C.M.O., 2001).

Segundo Buhler et al. (1992), a adoção de práticas de manejo de plantas daninhas que propiciem vantagem competitiva à cultura, como redução do espaçamento entre fileiras, permite diminuição na dose e no número de aplicações de herbicidas, reduzindo o custo de condução da lavoura e a contaminação do ambiente. O adensamento das plantas de beterraba proporcionou aumento na capacidade de supressão da cultura sobre as plantas daninhas (Carvalho \& Guzzo, 2008), podendo ser usado como ferramenta eficaz no manejo destas.

Outra prática que contribui para redução de plantas daninhas é a cobertura do solo, pois com a menor incidência de luz ocorre menor germinação de sementes dessas plantas. Ademais, em áreas de olericultura, onde o manejo das plantas daninhas é feito muitas vezes por capina manual, a economia de tempo e mão de obra pode ser grande, o que reduz o custo de produção e disponibiliza tempo e mão de obra para outras atividades.

O uso da cobertura morta envolvendo diferentes resíduos orgânicos é técnica que traz reconhecidos benefícios aos sistemas de produção, especialmente no que diz respeito ao manejo do solo e das plantas (Trezzi \& Vidal, 2004; Resende et al., 2005; Oliveira et al., 2008). Dentre as vantagens decorrentes de sua utilização, podem-se destacar a retenção de umidade, a melhoria da estrutura e menor compactação do solo (Corrêa, 2002), a prevenção à erosão (Smolikowski et al., 2001) e o aporte de matéria orgânica e nutrientes (Cadavid et al., 1998). Essa prática é indicada especialmente em sistemas de cultivo orgânico, como forma de controle de plantas daninhas, devido às restrições de uso de produtos químicos pelas entidades certificadoras (C.M.O., 2001) e pelo fato de a cobertura morta conservar a microbiota do solo e propiciar melhor qualidade do produto e do ambiente (Resende et al., 2005). 
Deve-se dar preferência aos materiais orgânicos obtidos nas propriedades ou imediações e a resíduos de agroindústrias da região, como palha de café, palha de arroz, bagaço de cana-de-açúcar triturado, capim seco e serragem (Deubert, 1997; Resende et al., 2005). Outros materiais, como capim-jaraguá (Hyparrhenia rufa) e capim-gordura (Melinis minutiflora), também se destacaram com potencial no controle de plantas daninhas quando utilizados como cobertura morta, sendo o capim-jaraguá $\left(6 \mathrm{~kg} \mathrm{~m}^{-2}\right)$ mais eficiente no controle de plantas dicotiledôneas. Os autores verificaram ainda que as coberturas mortas e os tratamentos com plástico e herbicida diminuíram o peso unitário e a produção de raízes de beterraba (Tozani et al., 2006). Há escassez de estudos relacionados ao controle físico das plantas daninhas em beterraba, como cobertura morta, impedindo a emergência de plantas. Acredita-se que o uso de cobertura morta no solo pode ser uma estratégia interessante para controlar plantas daninhas na cultura (Carvalho, 2009).

Considerando o ciclo relativamente curto das hortaliças, o sistema de sucessão dos cultivos e a demanda por adubos orgânicos e minerais, tornam-se importantes estudos que contemplam doses de fertilizantes alternativos na produção da beterraba. Sampaio et al. (2008) constataram aumento na massa fresca e seca de raízes de beterraba com o incremento na dose de composto de lixo, atingindo valores máximos com $90 \mathrm{t} \mathrm{ha}^{-1}$.

Objetivou-se avaliar o efeito da cobertura do solo com palha de café ou bagaço de canade-açúcar e de doses de lodo de lagoa de decantação de água residuária de suinocultura na incidência de plantas daninhas e na produtividade de raízes de beterraba, cultivar Early Wonder.

\section{MATERIAL E MÉTODOS}

O experimento foi realizado na Fazenda Experimental Vale do Piranga, pertencente à EPAMIG Zona da Mata, em Oratórios-MG, no período de 7 de agosto a 9 de novembro de 2008. A unidade de pesquisa está situada a $20^{\circ} 30^{\prime}$ de latitude $\mathrm{S}$ e $43^{\circ} 00^{\prime}$ de longitude $\mathrm{O}$, em altitude de $500 \mathrm{~m}$, com temperatura média máxima anual de $21,8^{\circ} \mathrm{C}$ e mínima anual de $19,5^{\circ} \mathrm{C}$; a precipitação pluvial média anual é de $1.250 \mathrm{~mm}$.

O solo, Argissolo Vermelho-Amarelo câmbico, fase terraço, apresentou na camada de 0 a $20 \mathrm{~cm}$ as seguintes características: $\mathrm{pH}$ (água 1:2,5) $=6,0$; matéria orgânica $=16 \mathrm{~g} \mathrm{~kg}^{-1}$; $\mathrm{P}=17,2 \mathrm{mg} \mathrm{dm}^{-3} ; \mathrm{K}=178 \mathrm{mg} \mathrm{dm}^{-3} \mathbf{e}$, expressos $\mathrm{em} \mathrm{cmol} \cdot \mathrm{dm}^{-3}, \mathrm{Ca}^{2+}=2,9 ; \mathrm{Mg}^{2+}=0,9 ; \mathrm{Al}^{3+}=0,0$; $\mathrm{CTC}(\mathrm{t})=4,26 ; \mathrm{CTC}(\mathrm{T})=6,90 ; \mathrm{V}=62 \% ;$ e P-rem $=35,6 \mathrm{mg} \mathrm{L}^{-1}$.

Utilizou-se o esquema de parcelas subdivididas no delineamento experimental de blocos casualizados, com quatro repetições. Nas parcelas foram dispostos três tipos de cobertura de solo: bagaço de cana-de-açúcar, palha de café e sem cobertura. Nas subparcelas foram aplicadas cinco doses $\left(0,10,20,40\right.$ e $\left.60 \mathrm{t} \mathrm{ha}^{-1}\right)$ de adubo orgânico proveniente de lodo de lagoa de decantação de águas residuárias de suinocultura. O lodo decantado na lagoa foi removido e transportado para o pátio de compostagem, para secagem, onde permaneceu por 30 dias.

As parcelas foram constituídas de canteiros com $1 \mathrm{~m}$ de largura e $10 \mathrm{~m}$ de comprimento. A subparcela (2 x $1 \mathrm{~m})$ foi composta de quatro fileiras de plantas espaçadas de $0,25 \mathrm{~m}$, sendo a área útil de $0,8 \mathrm{~m}^{2}$ central. Após o preparo dos canteiros, as doses de lodo foram aplicadas a lanço em área total e incorporadas, com enxada, na profundidade de 0 a $15 \mathrm{~cm}$. Em seguida, a superficie do canteiro foi coberta com uma camada de aproximadamente $2 \mathrm{~cm}$ de espessura, equivalente a $10 \mathrm{t} \mathrm{ha}^{-1}$ de bagaço de cana-de-açúcar triturado ou palha de café. A palha de café foi obtida na Fazenda Experimental da EPAMIG, em Oratórios-MG, da máquina beneficiadora de café em coco e café descascado, na qual estavam contidos casca (exocarpo), mucilagem (mesocarpo) e pergaminho (endocarpo). O bagaço de cana-deaçúcar foi obtido na usina de açúcar Jatiboca, em Santa Cruz do Escalvado-MG. As características dos resíduos orgânicos usados encontram-se na Tabela 1 .

As mudas de beterraba, cv. Early Wonder, foram produzidas em bandejas de poliestireno expandido com 200 células e transplantadas com 20 dias de idade e 21 dias após a aplicação do lodo. Logo após o transplante das mudas observou-se o ataque da lagarta-rosca (Agrotis ipsilon), em alguns tratamentos. 
O controle foi feito com aplicação do inseticida Dipel (Bacillus thuringiensis) na concentração de 30 g i.a. ha ${ }^{-1}$.

Aos 45 dias após o transplante, avaliou-se a incidência de plantas daninhas em cada subparcela. As espécies daninhas delimitadas por um gabarito de vergalhão de ferro de $0,50 \times 0,50 \mathrm{~m}$ foram cuidadosamente coletadas e, após retirada de resíduos de solo, pesadas para se obter a biomassa fresca total. Em seguida, as plantas foram identificadas e separadas em mono e dicotiledôneas. Dentro de monocotiledôneas, a tiririca foi separada das demais, por ser a espécie predominante. As plantas foram pesadas e colocadas em sacos de papel para secagem em estufa com circulação de ar, a $65^{\circ} \mathrm{C}$ por $72 \mathrm{~h}$, para obtenção da massa seca. Durante o ciclo da cultura não se utilizou outro método de controle de plantas daninhas, apenas os tratamentos mencionados. Após as avaliações das plantas daninhas foi feita uma capina nos corredores, em toda a área experimental.

A colheita foi realizada, manualmente, aos 70 dias após o transplante das mudas, quando a maioria das raízes tuberosas apresentava, visualmente, o tamanho preferido pelo mercado, ou seja, entre 200 e 300 g. Antes da

Tabela 1 - Características da palha de café, do bagaço de canade-açúcar e do lodo de lagoa de decantação de águas residuárias de suinocultura. Oratórios-MG, EPAMIG, 2008

\begin{tabular}{|l|c|r|c|r|}
\hline Característica & Unidade & $\begin{array}{c}\text { Palha de } \\
\text { café }\end{array}$ & $\begin{array}{c}\text { Bagaço de } \\
\text { cana-de-açúcar }\end{array}$ & $\begin{array}{r}\text { Lodo de } \\
\text { lagoa }^{1}\end{array}$ \\
\hline $\mathrm{N}$ & $\mathrm{g} \mathrm{kg}^{-1}$ & 23,5 & 2,0 & 9,0 \\
\hline $\mathrm{P}$ & $\mathrm{g} \mathrm{kg}^{-1}$ & 1,3 & 0,4 & 42,0 \\
\hline $\mathrm{K}$ & $\mathrm{g} \mathrm{kg}^{-1}$ & 48 & 1,6 & 2,4 \\
\hline $\mathrm{Ca}$ & $\mathrm{g} \mathrm{kg}^{-1}$ & 10,8 & 1,7 & 132,0 \\
\hline $\mathrm{Mg}$ & $\mathrm{g} \mathrm{kg}^{-1}$ & 1,2 & 0,2 & 4,2 \\
\hline $\mathrm{S}$ & $\mathrm{g} \mathrm{kg}^{-1}$ & 1,2 & 0,1 & 4,4 \\
\hline $\mathrm{Zn}$ & $\mathrm{mg} \mathrm{kg}^{-1}$ & 31 & 9,0 & 1.359 \\
\hline $\mathrm{Fe}$ & $\mathrm{mg} \mathrm{kg}^{-1}$ & 925 & 1.082 & 6.187 \\
\hline $\mathrm{Mn}$ & $\mathrm{mg} \mathrm{kg}^{-1}$ & 139 & 73 & 1.364 \\
\hline $\mathrm{Cu}$ & $\mathrm{mg} \mathrm{kg}^{-1}$ & 27 & 1,0 & 573 \\
\hline $\mathrm{B}$ & $\mathrm{mg} \mathrm{kg}^{-1}$ & 22,4 & 13,1 & 12 \\
\hline $\mathrm{Densidade}$ & $\mathrm{kg} \mathrm{dm}^{-3}$ & 0,12 & 0,05 & 0,82 \\
\hline $\mathrm{Umidade}$ & $\%$ & 10 & 9,8 & 38,2 \\
\hline $\mathrm{C} / \mathrm{N}$ & - & 11,5 & 132 & 2,42 \\
\hline $\mathrm{pH}$ & - & 6,7 & 5,9 & 7,0 \\
\hline
\end{tabular}

${ }^{1 /}$ Lodo proveniente do fundo de lagoa de estabilização de águas residuárias de suinocultura colheita, mediu-se a altura de 10 plantas e contou-se o número de plantas, na área útil da subparcela. Então, as plantas foram colhidas e pesadas, para obtenção da massa fresca total. Posteriormente, as raízes foram separadas da parte aérea, pesadas e, de acordo com o calibre, classificadas em comercial (classes 50,90 e $120 \mathrm{~mm}$ ) e não comercial (refugo mais raízes com defeitos graves), de acordo com HORTBRASIL (2008). As classes de raízes de beterraba são: classe 50 (maior ou igual a 50 e $<90 \mathrm{~mm}$ ), classe 90 (maior ou igual a 90 e $<120 \mathrm{~mm}$ ), classe 120 (> $120 \mathrm{~mm}$ ) e refugo $(<50 \mathrm{~mm})$. Calculou-se também a massa fresca unitária das raízes comerciais.

Amostras de raizes comerciais de cada tratamento foram lavadas e secas ao ar, cortadas ao meio e raladas em ralador inox, para determinação do teor de sólidos solúveis (Brix) no extrato, por meio de um refratômetro digital Atago, modelo PR-101 (escala 0 - $45 \%$ ), ajustado à temperatura de $25^{\circ} \mathrm{C}$.

Os dados obtidos foram submetidos à análise de variância e de regressão; quando significativos, a comparação entre médias foi feita pelo teste de Tukey $(\mathrm{P}<0,05)$, utilizando-se o software SAEG (2007).

\section{RESULTADOS E DISCUSSÃO}

As espécies daninhas predominantes na área experimental foram: tiririca (Cyperus rotundus), botão-de-ouro (Siegesbeckia orientalis), capim-marmelada (Brachiaria plantaginea), corda-de-viola (Ipomoea grandifolia), picão-preto (Bidens pilosa), caruru (Amaranthus spp.) e mentrasto (Ageratum conyzoides). Não houve interação entre tipos de cobertura e doses de lodo de lagoa, para as características avaliadas. Contudo, houve efeito isolado de tipos de cobertura morta sobre massa fresca de plantas daninhas (MFPD), massa seca de tiririca (MST), densidade de plantas monocotiledôneas (DPM), massa seca de dicotiledôneas (MSD) e densidade de plantas dicotiledôneas (DPD), bem como das doses de lodo sobre a massa seca de monocotiledôneas (MSM), com exceção da tiririca, independentemente do tipo de cobertura morta.

Os coeficientes de variação apresentaram valores elevados, provavelmente, devido à 
ocorrência espontânea de plantas, ou seja, não se fez distribuição de sementes na área experimental; ainda assim, houve efeito de tipos de cobertura no controle de plantas daninhas. A palha de café e o bagaço de cana-deaçúcar foram eficientes na redução de plantas daninhas, sendo observadas menores massa fresca total (MFPD) e massa seca de plantas dicotiledôneas (MSD), além de menor densidade de plantas monocotiledôneas e dicotiledôneas nos tratamentos com cobertura morta, em relação à testemunha (Tabela 2). Esses resultados comprovam os obtidos por Tozani et al. (2006), que verificaram maior eficiência da cobertura morta no controle de plantas daninhas dicotiledôneas, no cultivo de beterraba. Esse fato pode estar relacionado à maior incidência de sementes de espécies dicotiledôneas na área. A cobertura morta pode ter efeito supressivo pela inibição da germinação e emergência de plantas por efeitos físico, químico e biológico, envolvendo redução na disponibilidade de radiação solar, redução da amplitude térmica e liberação de compostos orgânicos e/ou efeito alelopático (Trezzi \& Vidal, 2004). Oliveira et al. (2008) observaram que as coberturas mortas usadas na cultura da alface foram eficientes no controle da vegetação espontânea, independentemente do material utilizado.

A palha de café aumentou a massa seca de tiririca (MST), em relação aos tratamentos sem cobertura e com bagaço de cana-de-açúcar, porém a massa seca das outras monocotiledôneas (MSM) não foi influenciada pela cobertura do solo. Observa-se que, numericamente, maior valor de MSM também foi obtido com palha de café como cobertura (Tabela 2). Provavelmente, a estrutura física da palha de café tenha facilitado a entrada de luz e a emergência das plantas, além da manutenção da umidade e, possivelmente, absorção de nutrientes, resultando no aumento de MST em relação aos demais tratamentos.

A densidade de plantas de tiririca não foi influenciada pela cobertura morta. Silva et al. (2010) afirmam que a cobertura morta é uma boa e eficiente prática para o controle de plantas daninhas, exceto tiririca e trevo; em razão disso, ela é indicada apenas em áreas onde há necessidade de economia de água na irrigação e a tiririca e o trevo ainda não estejam presentes.

Houve decréscimo linear na produção de massa seca das monocotiledôneas, exceto da tiririca, com o aumento da dose de lodo (Figura 1). Esse resultado pode ser atribuído ao maior teor de nutrientes disponíveis, com o aumento das doses de lodo, o que proporcionou melhores condições para o crescimento das plantas de beterraba, tornando-as mais competitivas com as monocotiledôneas, à exceção da tiririca, que foi avaliada separadamente. Além disso, o plantio da beterraba foi feito por muda, o que proporcionou estabelecimento mais rápido da cultura em relação à germinação e crescimento das plantas daninhas.

Em relação ao controle de plantas daninhas com cobertura morta, verificou-se que tanto a palha de café quanto o bagaço de cana-de-açúcar

Tabela 2 - Massa fresca total de plantas daninhas (MFPD), massa seca (MS) por subparcela e densidade de plantas (DP) de tiririca, de monocotiledônea e de dicotiledônea em canteiros de beterraba cultivada com cobertura morta e adubada com lodo de lagoa de decantação de águas residuárias de suinocultura. Oratórios-MG, EPAMIG, 2008

\begin{tabular}{|l|c|c|c|c|c|c|c|}
\hline \multirow{2}{*}{ Cobertura Morta } & \multirow{2}{*}{ MFPD } & \multicolumn{2}{|c|}{ Tiririca } & \multicolumn{2}{c|}{ Monocotiledônea } & \multicolumn{2}{c|}{ Dicotiledônea } \\
\cline { 2 - 7 } & & MS & DP & MS $^{1 /}$ & DP & MS & DP \\
\cline { 2 - 7 } & $(\mathrm{g})$ & $(\mathrm{g})$ & $\left(\mathrm{pls} . \mathrm{m}^{-2}\right)$ & $(\mathrm{g})$ & $\left(\mathrm{pls} . \mathrm{m}^{-2}\right)$ & $(\mathrm{g})$ & $\left(\mathrm{pls} . \mathrm{m}^{-2}\right)$ \\
\hline Sem cobertura & $315,75 \mathrm{a}$ & $0,90 \mathrm{~b}$ & $5,05 \mathrm{a}$ & $4,77 \mathrm{a}$ & $30,80 \mathrm{a}$ & $35,97 \mathrm{a}$ & $71,00 \mathrm{a}$ \\
\hline Palha de café & $153,00 \mathrm{~b}$ & $3,38 \mathrm{a}$ & $8,75 \mathrm{a}$ & $5,44 \mathrm{a}$ & $9,85 \mathrm{~b}$ & $9,51 \mathrm{~b}$ & $8,60 \mathrm{c}$ \\
\hline Bagaço de cana & $122,50 \mathrm{~b}$ & $1,42 \mathrm{~b}$ & $7,60 \mathrm{a}$ & $3,91 \mathrm{a}$ & $7,90 \mathrm{~b}$ & $9,32 \mathrm{~b}$ & $19,10 \mathrm{~b}$ \\
\hline Médias & 197,08 & 1,90 & 7,13 & 4,71 & 16,18 & 18,27 & 32,90 \\
\hline CV $(\%)$ & 78,82 & 84,04 & 86,78 & 78,76 & 92,09 & 114,12 & 46,90 \\
\hline
\end{tabular}

${ }_{1 /} \mathrm{MSM}=$ massa seca de monocotiledôneas, excluindo a tiririca. A área útil da subparcela é de $0,8 \mathrm{~m}^{2}$.

Médias seguidas pela mesma letra minúscula não diferem entre si a $5 \%$ de probabilidade pelo teste de Tukey. 


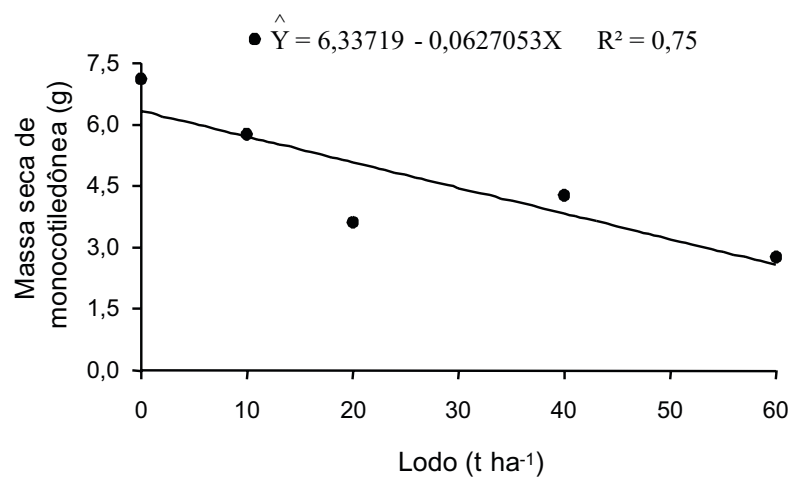

Figura 1 - Massa seca de plantas daninhas monocotiledônea, exceto tiririca, em canteiros de beterraba cultivada com cobertura morta e adubada com doses de lodo de lagoa de decantação de água residuária de suinocultura. OratóriosMG, EPAMIG, 2008

foram eficientes em reduzir a massa fresca total, a densidade de plantas mono e dicotiledôneas e a massa seca das plantas dicotiledôneas, porém a escolha dependerá da disponibilidade desses materiais nas regiões de cultivo, procurando, dessa forma, minimizar os custos.

Na beterraba, não houve interação entre cobertura morta e doses de lodo para as características avaliadas, mas houve efeito para tipos de cobertura morta. A cobertura com palha de café apresentou o menor número de plantas de beterraba $(26,05)$ por subparcela $\left(0,8 \mathrm{~m}^{2}\right)$, em relação ao tratamento sem cobertura morta $(28,65)$, porém ambos não diferiram do tratamento com bagaço de cana-de-açúcar (Tabela 3). Esse fato pode estar relacionado ao dano causado pela lagarta-rosca (Agrotis ipsilon), no tratamento com palha de café, logo após o transplante das mudas, com perdas de plantas e necessidade de replantio. Provavelmente, a maior umidade no solo - condição favorável à lagarta-rosca - e a barreira física criada pela palha ao inseticida Dipel prolongaram o periodo de ataque dessa praga às mudas recém-plantadas. Observou-se redução significativa no estande de plantas, devido à ocorrência de lagarta-rosca no sistema de plantio direto em regiões produtoras de feijão, em razão da maior cobertura do solo pela palhada (Quintela, 2005).

A altura das plantas de beterraba foi maior no solo sem cobertura morta e no solo coberto com palha de café (Tabela 3). O bagaço de canade-açúcar proporcionou menor altura de plantas, provavelmente, devido à menor concentração de $\mathrm{N}$ e à lenta decomposição do material, que tem alta relação $\mathrm{C} / \mathrm{N}(132 / 1)$, conforme se observa na Tabela 1. Maior produção de massa fresca da parte aérea foi obtida no tratamento com palha de café, em relação ao bagaço de cana-de-açúcar e solo sem cobertura morta, enquanto a produtividade de massa seca da parte aérea não diferiu entre os tipos de cobertura morta. Uma explicação para o fato pode ser a maior umidade do solo nos canteiros cobertos com palha de café, proporcionando maior absorção de água pelas plantas de beterraba.

A maior massa unitária da raiz $(293,85$ g) ocorreu no tratamento com palha de café, em relação ao tratamento sem cobertura, porém sem diferir do tratamento com bagaço de canade-açúcar (Tabela 3). A explicação poderia estar tanto na melhor absorção de água nos tratamentos com cobertura morta, quanto na

Tabela 3 - Número de plantas por subparcela (NP)', altura média de plantas (AP), massa fresca da parte aérea (MFPA), massa seca da parte aérea (MSPA), massa unitária da raiz (MUR), produtividade de raízes comerciais (PRC) e de massa seca de raízes (MSR) de beterraba cultivada com cobertura morta e adubada com lodo de lagoa de decantação de águas residuárias de suinocultura. Oratórios-MG, EPAMIG, 2008

\begin{tabular}{|l|c|c|c|c|c|c|c|}
\hline Cobertura Morta & NP/subparcela & $\begin{array}{c}\text { AP } \\
(\mathrm{cm})\end{array}$ & $\begin{array}{c}\text { MFPA } \\
(\mathrm{g} \text { por planta) }\end{array}$ & $\begin{array}{c}\text { MSPA } \\
\left(\mathrm{t} \mathrm{ha}^{-1}\right)\end{array}$ & $\begin{array}{c}\text { MUR } \\
(\mathrm{g})\end{array}$ & $\begin{array}{c}\text { PRC } \\
\left(\mathrm{t} \mathrm{ha}^{-1}\right)\end{array}$ & $\begin{array}{c}\text { MSR } \\
\left(\mathrm{t} \mathrm{ha}^{-1}\right)\end{array}$ \\
\hline Sem cobertura & $28,65 \mathrm{a}$ & $50,13 \mathrm{a}$ & $80,89 \mathrm{~b}$ & $1,68 \mathrm{a}$ & $207,33 \mathrm{~b}$ & $32,15 \mathrm{~b}$ & $5,00 \mathrm{ab}$ \\
\hline Palha de café & $26,05 \mathrm{~b}$ & $50,08 \mathrm{a}$ & $102,90 \mathrm{a}$ & $1,84 \mathrm{a}$ & $293,85 \mathrm{a}$ & $38,66 \mathrm{a}$ & $5,44 \mathrm{a}$ \\
\hline Bagaço de cana & $27,00 \mathrm{ab}$ & $46,19 \mathrm{~b}$ & $84,59 \mathrm{~b}$ & $1,63 \mathrm{a}$ & $233,85 \mathrm{ab}$ & $31,84 \mathrm{~b}$ & $4,63 \mathrm{~b}$ \\
\hline Médias & 27,23 & 48,80 & 89,46 & 1,72 & 245,01 & 34,22 & 5,02 \\
\hline CV $(\%)$ & 10,02 & 5,59 & 17,33 & 19,15 & 34,47 & 19,70 & 17,95 \\
\hline
\end{tabular}

Médias seguidas pela mesma letra minúscula não diferem entre si a $5 \%$ de probabilidade pelo teste de Tukey.

${ }^{1 /} \mathrm{A}$ área útil da subparcela é de $0,8 \mathrm{~m}^{2}$. 
menor resistência do substrato de cultivo à expansão da raiz, especialmente na presença da palha de café, devido às suas características físicas. Não houve diferença estatística entre tratamentos para as diferentes classes de raízes. Maior concentração de raízes comerciais ocorreu na classe compreendida entre 50 e $90 \mathrm{~mm}(85,4 \%)$, seguida da classe 90 a $120 \mathrm{~mm}(14,6 \%)$, e não houve produção de raízes maior que $120 \mathrm{~mm}$.

Maior produtividade de raízes comerciais $\left(38,66 \mathrm{t} \mathrm{ha}^{-1}\right)$ e de massa seca de raizes $\left(5,44 \mathrm{t} \mathrm{ha}^{-1}\right)$ foi obtida com palha de café, diferindo significativamente da cobertura com bagaço de cana-de-açúcar, ao passo que a produção de massa seca de raízes foi semelhante à do tratamento sem cobertura morta (Tabela 3). Esses resultados podem ser atribuídos, provavelmente, à maior umidade do solo e ao maior fornecimento de nutrientes pela palha de café em decorrência de sua composição química e menor relação $\mathrm{C} / \mathrm{N}$ $(11,5 / 1)$, comparada à do bagaço de cana-deaçúcar (132/1), que para sua decomposição necessita de nutrientes do solo, especialmente o nitrogênio. Essa hipótese pode ser sustentada pela maior massa fresca da parte aérea, maior massa unitária de raiz e maior produtividade de raízes comerciais nos tratamentos com palha de café, em relação aos tratamentos sem cobertura morta e com cobertura de bagaço de cana-de-açúcar.

Nos três tipos de cobertura do solo avaliados, as raízes de beterraba apresentaram qualidade comercial e produtividade de 30 a $40 \mathrm{t} \mathrm{ha}^{-1}$, que se situa dentro da faixa média brasileira: 20 a $35 \mathrm{t} \mathrm{ha}^{-1}$. Esses resultados diferenciam daqueles obtidos por Tozani et al. (2006), que avaliaram o controle de plantas daninhas em beterraba com cobertura morta de capim-gordura e capim-jaraguá, nas quantidades de 2,4 e $6 \mathrm{~kg} \mathrm{~m}^{-2}$ aplicadas após a emergência, capim-gordura $\left(4 \mathrm{~kg} \mathrm{~m}^{-2}\right)$ após a semeadura, além de plástico preto, controle químico (herbicida EPTC) e testemunhas com e sem capina, e verificaram que todos os tratamentos reduziram o peso unitário e a produção de raízes em relação à testemunha com capina manual, que produziu $15,1 \mathrm{t} \mathrm{ha}^{-1}$.

A cobertura morta com materiais orgânicos de alta relação $\mathrm{C} / \mathrm{N}$, como o bagaço de canade-açúcar, pode prejudicar a produtividade de raízes de beterraba. De maneira geral, coberturas orgânicas com relação $\mathrm{C} / \mathrm{N}$ maior que 30:1 podem causar deficiência de $\mathrm{N}$ no solo, pela imobilização temporária durante o processo de decomposição (Robinson, 1988). Acredita-se que bons resultados podem ser conseguidos com a mistura da palha de café e bagaço de cana-de-açúcar, sendo, portanto, uma opção para os próximos estudos visando à produtividade de raízes comerciais e controle de plantas daninhas.

Houve correlação positiva entre massa fresca de parte aérea e massa fresca de raízes (comercial + refugo) para os tratamentos sem cobertura $(r=0,82)$, palha de café $(r=0,95)$ e bagaço de cana-de-açúcar $(r=0,89)$. A maior correlação obtida no tratamento com palha de café deve-se à influência da parte aérea na produção de massa fresca de raízes, ou seja, quanto maior a altura da planta e a massa fresca da parte aérea, maior a área foliar e maior a produção de fotoassimilados - consequência da melhor nutrição das plantas nesse tratamento.

Não houve efeito de tratamentos para o teor de sólidos solúveis, sendo obtido o valor médio de 8,61 ${ }^{\circ}$ Brix. Esse valor é semelhante aos citados em outros trabalhos para o cultivar Early Wonder (Marques et al., 2007; Sanches et al., 2008). De modo geral, o potássio influencia os teores de sólidos solúveis e aumenta os de açúcar nas raízes de beterraba. Apesar de o teor de $\mathrm{K}$ estar relativamente alto no solo e também na palha de café (Tabela 1), ele não foi suficiente para aumentar a concentração de sólidos solúveis nas raízes, ou seja, nem sempre maior disponibilidade de $\mathrm{K}$ vai promover mudanças no teor de sólidos solúveis nas raízes de beterraba, seja pelo tipo de solo, clima ou cultivar (Sanches et al., 2008), seja pela capacidade de utilização desse nutriente pelas plantas. Assim, o teor de sólidos solúveis parece ser uma característica inerente a cada cultivar, uma vez que Marques et al. (2007) também não encontraram diferenças no teor de sólidos solúveis e $\mathrm{pH}$ das raízes de beterraba cultivada com diferentes doses de esterco bovino.

Houve interação entre tipos de cobertura e doses de lodo de lagoa de decantação para a produção de raízes não comerciais. As maiores produções dessas raízes foram observadas quando o solo que recebeu $20 \mathrm{t} \mathrm{ha}^{-1}$ de lodo foi 
Tabela 4 - Produção de raízes não comerciais (refugo) de beterraba cultivada em três tipos de cobertura morta e adubada com lodo de lagoa de decantação de águas residuárias de suinocultura. Oratórios-MG, EPAMIG, 2008

\begin{tabular}{|l|c|c|c|c|c|c|}
\hline \multirow{2}{*}{ Cobertura } & \multicolumn{5}{|c|}{ Dose de lodo $\left(\mathrm{t} \mathrm{ha}^{-1}\right)$} & \multirow{2}{*}{ Média } \\
\cline { 2 - 7 } & 0 & 10 & 20 & 40 & 60 & 4,60 \\
\hline Sem cobertura & $5,19 \mathrm{aA}$ & $4,47 \mathrm{aA}$ & $6,25 \mathrm{bA}$ & $4,14 \mathrm{bA}$ & $2,94 \mathrm{bA}$ & 7,20 \\
\hline Palha de café & $6,38 \mathrm{aB}$ & $5,78 \mathrm{aB}$ & $3,02 \mathrm{bB}$ & $13,84 \mathrm{aA}$ & $6,92 \mathrm{aB}$ & 5,31 \\
\hline Bagaço de cana & $4,30 \mathrm{aB}$ & $4,30 \mathrm{aB}$ & $10,09 \mathrm{aA}$ & $3,06 \mathrm{bB}$ & $4,80 \mathrm{bB}$ & \\
\hline Médias & 5,29 & 4,85 & 6,45 & 7,03 & 4,89 & \\
\hline CV $(\%)$ & & 63,84 & & & \\
\hline
\end{tabular}

Médias seguidas pela mesma letra, maiúscula nas linhas e minúscula nas colunas, não diferem entre si a 5\% de probabilidade pelo teste de Tukey

coberto com bagaço de cana-de-açúcar e também quando o solo que recebeu 40 e $60 \mathrm{t} \mathrm{ha}^{-1}$ de lodo foi coberto com palha de café. Nos demais tratamentos, não houve diferenças para dose de lodo e tipo de cobertura (Tabela 4).

A palha de café proporcionou maior massa fresca de parte aérea e de raízes comerciais, independentemente da dose de lodo (Tabela 3). Assim, a maior produção de raízes não comerciais (refugo) pode estar relacionada à maior produção total de raízes, inclusive de raízes com defeitos graves, ou seja, refugo.

Com relação à infestação de plantas daninhas na cultura da beterraba, concluiu-se que a palha de café e o bagaço de cana-de-açúcar foram eficientes na redução da massa fresca total, da massa seca das plantas daninhas dicotiledôneas e da densidade de plantas daninhas mono e dicotiledôneas. Contudo, a cobertura com palha de café aumentou a massa seca de tiririca. O aumento nas doses de lodo reduziu a massa seca de plantas daninhas monocotiledôneas, exceto de tiririca. A produtividade de raízes comerciais e a massa fresca unitária de raiz de beterraba foram maiores com a palha de café, independentemente das doses de lodo aplicadas.

\section{AGRADECIMENTOS}

À Fundação de Amparo à Pesquisa do Estado de Minas Gerais (FAPEMIG), pelo auxilio financeiro do Programa Pesquisador Mineiro - PPM e pelas bolsas BIPDT e PDJ.

\section{LITERATURA CITADA}

BUHLER, D. D.; GUNSOLUS, J. L.; RALSTON, D. E. Integrated weed management techniques to reduce herbicide inputs. Agron. J., v. 84, n. 6, p. 973-978, 1992.
CADAVID, L. F. et al. Long-term effects of mulch, fertilization and tillage on cassava growth in sandy soils in Northern Colombia. Field Crops Res., v. 57, n. 1, p. 45-56, 1998.

C.M.O. Manual de certificação: Normas e procedimentos para o padrão de qualidade orgânico. 2.ed. São Paulo: Fundação Mokiti Okada, 2001. 34 p.

CARVALHO, L. B. Plantas daninhas afetam produtividade da beterraba. R. Campo Negócios, v. 5, n. 43 Disponível em: <http://www.revistacampoenegocios.com.br/anteriores/ 01-09/index.php?referencia=reportagemesp02 $>$ Acesso em: 22 set. 2009

CARVALHO, L. B. et al. Interferência e estudo fitossociológico da comunidade infestante na cultura da beterraba transplantada. Acta Sci. Agron., v. 30, n. 3, p. 325-331, 2008.

CARVALHO, L. B.; GUZZO, C. D. Adensamento da beterraba no manejo de plantas daninhas. Planta Daninha, v. 26, n. 1, p. $73-82,2008$.

CORREAA, J. C. Efeito de sistemas de cultivo na estabilidade de agregados de um Latossolo Vermelho-Amarelo em Querência, MT. Pesq. Agropec. Bras., v. 37, n. 2, p. 203-209, 2002.

DEUBERT, R. Ciências das plantas infestadas: manejo. Campinas: [s.n.], 1997. 285 p.

HORTA, A. C. S. et al. Interferência de plantas daninhas na beterraba transplantada e semeada diretamente. Acta Sci. Agron., v. 26, n. 1, p. 47-53, 2004.

HORTIBRASIL - Centro de Qualidade de Horticultura Norma de classificação da beterraba (Beta vulgaris L.). São Paulo: CQH/CEAGESP. Disponível em: <http://www. hortibrasil.org.br/rtbeterraba.doc $>$ Acesso em: 03/11/2008

KANNER, J.; HAREL, S.; GRANIT, R. Betalains: a new class of dietary cationized antioxidants. J. Agric. Food Chem., v. 49, n. 11, p. 5178-5185, 2001 
MARQUES, L. F. et al. Qualidade da beterraba em função de diferentes dosagens de esterco bovino. In: CONGRESSO BRASILEIRO DE OLERICULTURA, 47., 2007, Porto Seguro. Resumos... Porto Seguro: 2007. (ABH. Suplemento, v. 25) CD-ROM.

OLIVEIRA, F. F. et al. Avaliação de coberturas mortas em cultura de alface sob manejo orgânico. Hortic. Bras., v. 26, n. 2 , p. $216-220,2008$.

QUINTELA, E. D. Cultivo do feijão irrigado na região noroeste de Minas Gerais. Santo Antônio de Goiás, Embrapa/Arroz e Feijão, 2005. (Sistema de Produção, 5)

ROBINSON, D. W. Mulches in ornamental plantings. Author's reply. HortScience, v. 23, n. 6, p. 490-492, 1988

RESENDE, F. V. et al. Uso de cobertura morta vegetal no controle da umidade e temperatura do solo, na incidência de plantas invasoras e na produção da cenoura em cultivo de verão. Ci. Agrotec., v. 29, n. 1, p. 100-105, 2005

SAEG. Sistema para Análise Estatística. Versão 9.1. Viçosa, MG: Fundação Artur Bernardes. 2007.

SAMPAIO, R. A. et al. Produção e concentração de metais pesados em plantas de beterraba adubadas com composto de lixo urbano. Caatinga, v. 21, n. 5, p. 83-88, 2008
SANCHES, J., et al. Estudo comparativo de oito cultivares de beterraba mantidas sob condição ambiente. In: CONGRESSO BRASILEIRO DE OLERICULTURA, 48., 2008, Maringá. Resumos... Maringá: ABH, 2008. p. S43-S49. CD-ROM.

SILVA, A. C.; FERREIRA, F. A.; FERREIRA, L. R. Manejo integrado de plantas daninhas em hortaliças. Disponível em: $<$ http://www.apta.sp.gov.br/print.php?id=1932> Acesso em: 19 de março de 2010.

STAL, W. M.; DUSKY, J. A. Weed control in leafy vegetables (lettuce, endive, escarole and spinach). Disponível em: $<$ http://edis.ifas.ufl.edu/WG031 > Acesso em: 17 de junho de 2009.

SMOLIKOWSKI, B.; PUIG, H.; ROOSE, E. Influence of soil protection techniques on runoff, erosion and plant production on semiarid hillsides of Cabo Verde. Agric. Ecosyst. Environ., v. 87, n. 1, p. 67-80, 2001.

TREZZI, M. M.; VIDAL, R. A. Potencial de utilização de cobertura vegetal de sorgo e milheto na supressão de plantas daninhas em condição de campo: $I$ - efeitos da cobertura morta. Planta Daninha, v. 22, n. 1, p. 1-10, 2004.

TOZANI, R. et al. Manejo alternativo de plantas daninhas na cultura de beterraba. R. Univ. Rural, Sér. Ci. Vida, v. 25, n. 1-2, p. 70-78, 2006. 